\title{
Hubungan Fungsi Perawatan Kesehatan Keluarga Dengan Pemberian MP-ASI Pada Balita Usia 6-12 Bulan
}

\author{
Ni Luh Gede Puspita Yanti' ${ }^{1}$ I Gusti Ayu Putu Satya Laksmi² \\ 1,2,Program Studi Keperawatan Progra Sarjana, Stikes Wira Medika Bali
}

\begin{tabular}{|c|c|}
\hline $\begin{array}{c}\text { Info } \\
\text { Artikel }\end{array}$ & Abstrak \\
\hline $\begin{array}{l}\text { Article } \\
\text { History: } \\
\text { Accepted may } \\
\text { 28rd 2021 }\end{array}$ & $\begin{array}{l}\text { Pemberian Makanan Pendamping Air Susu Ibu secara dini pada anak dapat mengakibatkan } \\
\text { masalah di sistem pencernaan bayi, diantaranya diare, konstipasi, muntah dan alergi, } \\
\text { mempengaruhi tingkat kecerdasan. Dukungan keluarga mempengaruhi dalam pemberian MP- } \\
\text { ASI dan bermanfaat meningkatkan status kesehatan bayi \& balita dengan mengaplikasikan } \\
\text { fungsi perawatan kesehatan keluarga. Tujuan dari penelitian adalah mengetahui hubungan } \\
\text { fungsi perawatan kesehatan keluarga dengan pemberian MP-ASI pada balita usia } 6-12 \text { bulan. } \\
\text { Sampel yang digunakan adalah ibu balita usia } 6-12 \text { bulan, yang berada di wilayah kerja } \\
\text { Puskesmas Denpasar II Selatan, berjumlah } 63 \text { responden, menggunakan Teknik Purposive } \\
\text { Sampling. Instrument penelitian ini adalah kuesioner fungsi perawatan kesehatan keluarga } \\
\text { dan pemberian MP-ASI. Hasil dalam penelitian ini yaitu } 53(84,1 \%) \text { keluarga mampu } \\
\text { menerapkan fungsi perawatan kesehatan keluarga secara fungsional dan } 38(60,3 \%) \text { ibu } \\
\text { memberikan MP-ASI pada anak usia } 6-12 \text { bulan secara tepat, p value } 0,00<\alpha(0,05) \text {, yang } \\
\text { menunjukkan bahwa terdapat hubungan antara fungsi perawatan kesehatan keluarga dengan } \\
\text { pemberian MPASI. }\end{array}$ \\
\hline
\end{tabular}

Kata kunci :fungsi perawatan kesehatan, MP-ASI, balita

The Relationship of Family Health Care Function with Complementary Feeding (MP-ASI) For Toodlers aged 6-12 Months

Abstract

Complementary feeding of breastmilk to children can cause problems in the baby's digestive system, including diarrhea, constipation, vomiting and allergies, affecting the level of intelligence. Family support affects complementary feeding and is beneficial for improving the health status of infants \& toddlers by applying the family health care function. The aim of the study was to determine the relationship between family health care function and complementary feeding for toddlers aged 6-12 months. The sample used is the mother of a toddler aged 6-12 months, who are in the working area of the South Denpasar II Health Center, totaling 63 respondents, using purposive sampling technique. The research instrument was a family health care function questionnaire and complementary feeding. The results in this study were $53(84.1 \%)$ families were able to implement the family health care function functionally and $38(60.3 \%)$ mothers provided complementary foods to children aged 6-12 months appropriately, $\mathrm{p}$ value $0.00<\alpha(0.05)$, which indicates that there is a relationship between the family health care function and the provision of complementary foods.

Key words: health care function, complementary feeding, toddlers

Corresponding author:

Ni Luh Gede Puspita Yanti

Wika_puspitayanti@yahoo.com

Jurnal Ilmu Keperawatan Anak, Vol 4 No 1, May 2021

DOI: http://dx.doi.org/10.26594/jika.4.1.2021 19-26

e-ISSN 2621-296X 


\section{PENDAHULUAN}

Peraturan Pemerintah nomor 33 tahun 2012 tentang pemberian Air Susu Ibu Esklusif menyebutkan bahwa ASI eksklusif adalah ASI yang diberikan kepada bayi sejak dilahirkan selama enam bulan, tanpa menambahkan dan atau mengganti dengan makanan atau minuman lain (Pemerintah Republik Indonesia, 2012). Akan tetapi, pemberian MP-ASI sebelum usia enam bulan di Indonesia masih tergolong tinggi. Menurut data Profil Kesehatan indonesia, (2018), data bayi yang mendapat ASI eksklusif sebesar 61,33\% (target Renstra tahun 2017 yaitu 44\%). Cakupan pemberian ASI eksklusif tertinggi terdapat di Nusa Tenggara Barat (87,35\%), persentase terendah terdapat di Papua (15,32\%). Cakupan pemberian ASI eksklusif di Bali pada tahun 2017 sebesar 59,7\% (sesuai dengan target Renstra Kemenkes pada tahun 2019 yaitu sebesar 50\%). Selain itu, kabupaten/kota yang belum mencapai target yaitu Kabupaten Jembrana $(47,6 \%)$ dan Kota Denpasar (47,65\%)(Dinas Kesehatan Provinsi Bali, 2017). Tahun 2018 cakupan pemberian ASI Eksklusif sebesar $47,91 \%$ sudah mengalami peningkatan bila dibandingkan tahun 2017 (47,65\%). Hal ini berarti, pemberian MPASI pada bayi usia kurang dari 6 bulan masih sangat tinggi(Profil Kesehatan indonesia, 2018).

Pemberian MP-ASI lebih awal pada bayi dapat mengakibatkan masalah infeksi saluran pencernaan, pernafasan, penyakit obesitas, hipertensi dan penyakit jantung koroner. Kejadian tersebut merupakan salah satu penyebab tingginya angka kematian bayi di Indonesia (Nadesul, 2011). Bayi kurang dari enam bulan, kondisi sel-sel di sekitar ususnya belum siap dalam proses pemecahan dan penyerapan sari-sari makanan, sehingga menyebabkan reaksi imun ataupun terjadinya alergi (Luluk, 2005).

Faktor-faktor yang berhubungan dengan pemberian Makanan Pendamping ASI dini yaitu pekerjaan, kecukupan ASI, pengetahuan dan dukungan keluarga. Apabila pengetahuan ibu baik tentang pemberian MP-ASI , maka ibu tidak memberikan MP-ASI secara dini pada bayi. Pemberian ASI sebaiknya diberikan sesuai permintaan bayi termasuk pada malam hari. Bagi ibu yang bekerja mengalami kesulitan membagi waktu untuk memberikan ASI secara eksklusif sehingga sebagai alternatif mulai memberikan MP-ASI kepada bayinya ketika mereka berada di luar rumah. Dukungan keluarga yang baik akan membantu ibu untuk tidak memberikan makanan pendamping ASI kepada bayi mereka saat usia 0-6 bulan(Heryanto, 2017).

Dukungan keluarga bisa menjalankan fungsinya dalam perawatan kesehatan keluarga. Dimana perawatan kesehatan keluarga berfungsi untuk meningkatkan status kesehatan anggota keluarga, diantaranya dengan mampu mengenal masalah kesehatan, mampu mengambil keputusan tindakan kesehatan yang tepat, kemampuan merawat anggota keluarga, kemampuan mempertahankan suasana rumah yang menyenangkan dan memodifikasi lingkungan untuk menjamin kesehatan keluarga, kemampuan memanfaatkan fasilitas pelayanan kesehatan disekitarnya bagi keluarga (Andarmoyo, 2012). Berdasarkan penelitian Ayuningtiyas. Laksmi W, (2013), menyatakan ada hubungan yang signifikan antara pelaksanaan fungsi perawatan kesehatan keluarga dengan pencapaian tahap perkembangan balita.

Berdasarkan studi pendahuluan, didapatkan cakupan ASI Eksklusif terendah di Kota Denpasar yaitu di Puskesmas II Denpasar Selatan $(44,83 \%)$. Angka ini masih sangat jauh dari target Renstra Kemenkes yaitu $50 \%$. Tujuan dari penelitian yaitu mengetahui hubungan fungsi perawatan kesehatan keluarga dengan pemberian MPASI pada balita usia 6-12 bulan. 


\section{METODE}

Metode yang digunakan dalam penelitian adalah metode kuantitatif, pendekatan penelitian deskriptif korelasional, dan jenis penelitiannya cross sectional study untuk membuktikan hubungan antara penyebab (masalah) dengan efek suatu fenomena pada satu saat tertentu(Nursalam, 2017). Variabel pada penelitian ini yaitu fungsi perawatan kesehatan keluarga (variabel independen) dan pemberian MP-ASI (variabel dependen).

Populasi dalam penelitian yaitu orangtua balita usia 6-12 bulan sejumlah 76 orang tua, dengan jumlah sampel 63 responden. Kriteria sampel pada penelitian yaitu orangtua yang mempunyai anak dengan riwayat kehamilan cukup bulan serta anak tidak mengalami gangguan mental, cacat fisik, penyakit kronis, dan penyakit kongenital. Sampel diambil menggunakan teknik purposive sampling. Pelaksanaan penelitian yaitu di wilayah kerja Puskesmas II Denpasar Selatan, pada bulan Agustus 2020.

Instrumen menggunakan kuesioner fungsi perawatan kesehatan keluarga dan pemberian MPASI pada balita usia 6-12 bulan. Kuesioner telah dilakukan uji validitas dengan menggunakan uji korelasi Pearson Product Moment terhadap 30 responden, hasil didapatkan nilai $r$ hitung lebih besar dari $r$ tabel, yaitu hasil lebih besar dari 0,361 sehingga kuesioner dikatakan valid. Hasil uji reliabilitas dikatakan reliabel dengan nilai alpha Cronbach sebesar 0,989 .

Pengambilan data diawali dengan melakukan persamaan persepsi dengan penanggung jawab program Kesehatan Ibu dan Anak di Puskesmas II Denpasar Selatan serta kader dari masing-masing banjar. Selanjutnya menentukan responden berdasarkan kriteria yang dilakukan dengan tatap muka daring, sekaligus menjelaskan maksud, tujuan dan proses pengambilan data penelitian. Orangtua yang bersedia menjadi responden diundang dalam grup komunikasi online untuk memudahkan pengambilan data.Kuesioner kemudian dibagikan melalui google form, hal ini karena pengambilan data dilaksanakan selama masa pandemic Covid 19.

Analisa data univariate dilakukan untuk mengetahui distribusi frekuensi pelaksanaan fungsi perawatan kesehatan keluarga dan pemberian MP-ASI pada balita.Analisa bivariate menggunakan Uji Spearman Rho untuk mengetahui hubungan kedua variabel dengan menggunakan taraf signifikan $5 \%$.

Etika penelitian yang diterapkan dalam penelitian di antaranya: meminta persetujuan dengan menggunakan informed consent yang diberikan melalui google form bagi yang bersedia menjadi responden; identitas responden dicantumkan dengan menggunakan inisial; semua subjek diberikan perlakuan yang sama tanpa membeda-bedakan; data hasil penelitian dirahasiakan dan di aplikasikan dalam kepentingan penelitian; tidak mengancam keselamatan, tidak merugikan responden.

\section{HASIL}

Data yang disajikan yaitu karakteristik responden (usia, pendidikan ibu), data variabel fungsi perawatan kesehatan keluarga dan pemberian MP-ASI, serta hubungan kedua variabel.

Tabel 1

Distribusi Responden (Usia, Pekerjaan dan Pendidikan Ibu)

\begin{tabular}{lccc}
\hline \multicolumn{1}{c}{ Usia Ibu } & Mean & Min & Max \\
\hline Usia Ibu & 27 & 20 & 35 \\
\hline Pekerjaan Ibu & Frekuensi & Persentase \\
IRT & 17 & 27 \\
Buruh & 4 & 6,3 \\
Wiraswasta & 22 & 35 \\
PNS & 20 & 31,7 \\
Total & 63 & 100 \\
\hline
\end{tabular}

\begin{tabular}{lcc}
\multicolumn{1}{c}{ Pendidikan Ibu } & Frekuensi & Persentase \\
SMP & 2 & 3,2 \\
SMA & 34 & 53,9 \\
PT & 27 & 42,9 \\
Total & & 230 \\
\hline
\end{tabular}


Tabel 2

Distribusi Fungsi Perawatan Kesehatan Keluarga dan Pemberian MP-ASI

\begin{tabular}{lcc}
\hline \multicolumn{1}{c}{ Variabel } & Frekuensi & Persentase \\
\hline $\begin{array}{l}\text { Fungsi perawatan } \\
\text { kesehatan keluarga }\end{array}$ & & \\
Fungsional & 53 & 84,1 \\
Disfungsional & 10 & 15,9 \\
Total & 63 & 100 \\
\hline$\quad$ Pemberian MPASI & & \\
MPASI yang tepat & 38 & 60,3 \\
MPASI yang tidak & 25 & 39,7 \\
tepat & & \\
Total & 63 & 100 \\
\hline
\end{tabular}

Tabel 3

Tabel Silang antara Fungsi Perawatan Kesehatan Keluarga dengan Pemberian MPASI

\begin{tabular}{|c|c|c|c|c|c|c|}
\hline \multirow{3}{*}{$\begin{array}{l}\text { Fungsi } \\
\text { perawatan } \\
\text { kesehatan } \\
\text { keluarga }\end{array}$} & \multicolumn{6}{|c|}{ Pemberian MPASI } \\
\hline & \multicolumn{2}{|c|}{ Tepat } & \multicolumn{4}{|c|}{$\begin{array}{l}\text { Tidak } \\
\text { Tepat }\end{array}$} \\
\hline & $\mathrm{f}$ & $\%$ & $\mathrm{f}$ & $\%$ & $\begin{array}{c}\mathrm{p} \\
\text { value }\end{array}$ & \\
\hline Fungsional & 38 & 60,3 & 15 & 23,8 & 0,000 & 0,5 \\
\hline Disfungsional & 0 & 0 & 10 & 15,9 & & \\
\hline Total & 38 & 60,3 & 25 & 39,7 & & \\
\hline
\end{tabular}

\section{PEMBAHASAN}

Hasil penelitian yang telah dilakukan dapat diketahui bahwa sebagian besar keluarga mampu menerapkan fungsi perawatan kesehatan keluarga secara fungsional.

Hasil penelitian tidak selaras dengan penelitian sebelumnya (Ayuningtiyas. Laksmi W, 2013). Hasil penelitian menunjukkan bahwa pelaksanaan fungsi perawatan kesehatan dilakukan dengan baik oleh sebagian besar responden yaitu 19 responden $(59,3 \%)$. Hal ini membuktikan bahwa peran keluarga untuk menerapkan fungsi perawatan kesehatan masih tergolong kurang.

Keluarga merupakan kelompok orang terdekat yang mampu memenuhi segala kebutuhan khususnya dalam hal kesehatan, keluarga wajib memahami fungsi keluarga dalam memberikan perawatan kesehatan (Efendy Nasrul, 1998). Dalam melaksanakan fungsi tersebut, keluarga harus mengawali dengan kemampuan dalam mendeteksi adanya keluhan kesehatan keluarga. Keluarga diharapkan mampu mengetahui jika terdapat masalah perkembangan balita yang meliputi defenisi, tanda dan gejala, penyebab serta persepsi keluarga tentang perawatan dan pemenuhan kebutuhan balita sehingga balita dapat tumbuh dan berkembang sesuai dengan usianya. Keluarga yang mampu mengetahui adanya masalah kesehatan anggota keluarga sejak awal maka akan meminimalkan pengeluaran dana keluarga (Suprajitno, 2004). Nutrisi yang dibutuhkan balita harus diketahui oleh keluarga agar keluarga mampu memenuhinya dengan baik.

Pemahaman terhadap masalah kesehatan keluarga nantinya akan dapat dijadikan dasar dalam membuat atau mengambil keputusan terkait masalah kesehatan keluarga. Kemampuan keluarga dalam ,53æengambil keputusan adalah bagaimana keluarga memahami tentang sifat dan luasnya masalah, apakah keluarga merasakan adanya maslaah, menyerah terhadap masalah kesehatan yang ada, takut terhadap efek dari tindakan, bersikap negatif terhadap masalah kesehatan. Fungsi ini adalah upaya keluarga untuk mendapatkan pertolongan yang sesuai dengan kondisi kesehatan keluarga. Keluarga harus mempertimbangkan orang yang tepat untuk bertugas mengambil keputusan tindakan yang tepat sesuai kebutuhan (Suprajitno, 2004). Keluarga yang mengambil keputusan kesehatan diharapkan tepat agar pemenuhan nutrisi pada balita sesuai dengan kebutuhannya.

Keluarga selanjutnya diharapkan mampu memberikan perawatan pada keluarga yang skit. Memberikan perawatan anggota keluarga merupakan sejauh mana keluarga dapat mengidentifikasi sejak awal keadaan penyakitnya, memahami perkembangan kondisi kesehatan selama mendapatkan perawatan, mengetahui kemampuan yang dimiliki keluarga, mengetahui fasilitas kesehatan yang diperlukan yang mudah 
dijangkau untuk mendapatkan perawatan dan sikap keluarga terhadap anggota keluarga yang sakit. Keluarga dapat merawat keluarga sejak awal terjadinya kondisi sakit, sehingga dapat meminimalkan kondisi penyakit yang semakin parah (Setiadi, 2008).

Memodifikasi lingkungan juga penting untuk mampu dilakukan oleh keluarga. Lingkungan rumah yang terpelihara dengan baik dapat mempengaruhi kesehatan balita, jika tidak mampu dilaksanakan maka akan mengakibatkan ketidakseimbangan pada sumber-sumber keluarga, anggota keluarga tidak memiliki tanggung jawab dan wewenang, kurang merasakan keuntungan serta manfaat memelihara lingkungan bagi kesehatan balita, tidak tahu bahwa lingkungan yang bersih itu sangat penting, dan ketidakkompakan keluarga. Kesehatan balita dapat dicapai dengan maksimal jika lingkungan sekitarnya nyaman (Ramlah, 2011).

Keluarga dalam mempertahankan dan meningkatkan kesehatan anggota keluarga dapat dengan memanfaatkan fasilitas kesehatan. Keluarga yang mampu menjalankan fungsi ini ditandai dengan mampu mengetahui adanya fasilitas kesehatan yang mudah dijangkau yang dapat dimanfaatkan oleh keluarga, keluarga percaya terhadap petugas kesehatan. Keluarga mampu memanfaatkan dengan melakukan kunjungan ke fasilitas kesehatan yang sering dikunjungi dan lokasinya yang mudah dijangkau (Ayuningtiyas. Laksmi W, 2013).

Pendidikan seseorang dapat mempengaruhi fungsi perawatan kesehatan keluarga. Responden pada penelitian ini sebagian besar merupakan lulusan SMA. Hasil ini sejalan dengan penelitian Ayuningtiyas. Laksmi W, (2013), dimana $50 \%$ responden memiliki latar belakang pendidikan SD sehingga responden tidak mampu melaksanakan fungsi perawatan kesehatan dengan baik. Wawasan dari ibu yang memiliki tingkat pendidikan tinggi akan lebih terbuka dan mampu objektif dalam memutuskan suatu hal atau tindakan yang diterapkan sebagai suatu perilaku yang positif. Sebaliknya perkembangan sikap ibu terhadap suatu hal yang baru akan terhambat jika tingkat pendidikannya lebih rendah, terutama dalam melaksanakan fungsi perawatan kesehatan keluarga untuk mencapai tugas perkembangan balita.

Pekerjaan merupakan faktor berikutnya yang dapat mempengaruhi pelaksanaan fungsi perawatan kesehatan keluarga. Responden pada penelitian ini sebagian besar ibu bekerja. Pengalaman akan lebih banyak diperoleh pada orang yang bekerja, akan menambah pengetahuan baru dan terus berkembang. Sebaliknya orang tua/pengasuh balita akan sedikit memperoleh pengalaman dan pengetahuan jika tidak bekerja, karena paparan terhadap informasi akan lebih minimal.

Penelitian yang dilakukan di wilayah kerja Puskesmas II Denpasar Selatan didapatkan hasil bahwa sebagian besar mampu memberikan MPASI secara tepat, pendidikan responden pada penelitian sebagian besar SMA. Faktor-faktor yang mempengaruhi adalah pekerjaan ibu, kesehatan, pengetahuan, iklan MP-ASI, petugas kesehatan, budaya dan sosial ekonomi. Pengetahuan sangat berpengaruh pada pola pikir terhadap sesuatu hal yang akhirnya akan mempengaruhi terjadinya perubahan perilaku. Semakin tinggi pengetahuan seseorang, maka cenderung peduli terhadap masalah kesehatan (dirinya/keluarganya) termasuk dalam memberikan MPASI pada bayi usia $\leq 6$ bulan (Notoatmodjo, 2014). Faktor yang dapat menghambat kelangsungan pemberian ASI yaitu keyakinan ibu. Seperti pernyataan yang mengatakan bahwa ibu yakin bahwa bayi tidak akan cukup memperoleh zat gizi jika hanya diberi ASI sampai umur 6 bulan (Heryanto, 2017).

Hasil penelitian lainnya menunjukkan sebagian besar ibu bekerja. Hasil penelitian (Rahmawati \& Prayogi, 2017), menunjukkan 
bahwa produksi ASI tidak ada hubungannya dengan pendidikan, pekerjaan dan dukungan suami/keluarga dan ada hubungannya dengan lama kerja, penambahan susu formula dan frekuensi memerah. Sebagian besar ibu bekerja telah memiliki keinginan untuk memberikan ASI eksklusif sejak dari mengandung, namun setelah mulai bekerja lagi produksi ASI menjadi sedikit dan tidak mencukupi kebutuhan bayi sehingga ibu berinisiatif untuk memberikan tambahan susu formula (Anggraenil, I.A., D.S. Nurdiati, 2015).

Hasil penelitian ini juga menunjukkan ada hubungan fungsi perawatan kesehatan keluarga dengan pemberian MPASI. Salah satu penyebab meningkatnya angka kesakitan pada bayi yaitu pemberian makanan padat/tambahan yang terlalu dini, hal ini terjadi karena bayi usia kurang dari 6 bulan memiliki sistem imun yang belum sempurna. Selain itu, tidak ditemukan bukti yang mendukung bahwa pemberian makanan padat atau tambahan pada usia 45 bulan lebih membawa dampak positif. Sebaliknya, memberikan dampak negatif terhadap kesehatan bayi (Roesli Utami, 2004).

Penelitian yang dilakukan di wilayah kerja Puskesmas II Denpasar Selatan didapatkan hasil bahwa sebagian besar mampu memberikan MPASI secara tepat, pendidikan responden pada penelitian sebagian besar SMA. Faktor-faktor yang mempengaruhi adalah pekerjaan ibu, kesehatan, pengetahuan, iklan MP-ASI, petugas kesehatan, budaya dan sosial ekonomi. Pengetahuan sangat berpengaruh pada pola pikir terhadap sesuatu hal yang akhirnya akan mempengaruhi terjadinya perubahan perilaku. Semakin tinggi pengetahuan seseorang, maka cenderung peduli terhadap masalah kesehatan (dirinya/keluarganya) termasuk dalam memberikan MPASI pada bayi usia $\leq 6$ bulan (Notoatmodjo, 2014). Faktor yang dapat menghambat kelangsungan pemberian ASI yaitu keyakinan ibu. Seperti pernyataan yang mengatakan bahwa ibu yakin bahwa bayi tidak akan cukup memperoleh zat gizi jika hanya diberi ASI sampai umur 6 bulan (Heryanto, 2017).

Hasil penelitian lainnya menunjukkan sebagian besar ibu bekerja. Hasil penelitian (Rahmawati \& Prayogi, 2017), menunjukkan bahwa produksi ASI tidak ada hubungannya dengan pendidikan, pekerjaan dan dukungan suami/keluarga dan ada hubungannya dengan lama kerja, penambahan susu formula dan frekuensi memerah. Sebagian besar ibu bekerja telah memiliki keinginan untuk memberikan ASI eksklusif sejak dari mengandung, namun setelah mulai bekerja lagi produksi ASI menjadi sedikit dan tidak mencukupi kebutuhan bayi sehingga ibu berinisiatif untuk memberikan tambahan susu formula (Anggraenil, I.A., D.S. Nurdiati, 2015).

Hasil penelitian ini juga menunjukkan ada hubungan fungsi perawatan kesehatan keluarga dengan pemberian MPASI. Salah satu penyebab meningkatnya angka kesakitan pada bayi yaitu pemberian makanan padat/tambahan yang terlalu dini, hal ini terjadi karena bayi usia kurang dari 6 bulan memiliki sistem imun yang belum sempurna. Selain itu, tidak ditemukan bukti yang mendukung bahwa pemberian makanan padat atau tambahan pada usia 45 bulan lebih membawa dampak positif. Sebaliknya, memberikan dampak negatif terhadap kesehatan bayi (Roesli Utami, 2004).

\section{SIMPULAN}

Fungsi perawatan kesehatan keluarga mempunyai hubungan yang sangat signifikan dengan pemberian MPASI pada anak usia 6-12 tahun, semakin baik keluarga dalam menerapkan fungsinya dalam memberikan perawatan kesehatan keluarga, maka pemberian MPASI akan bisa diberikan dengan cara yang tepat pada balita. Petugas kesehatan diharapkan agar selalu dapat memberikan edukasi mengenai fungsi perawatan kesehatan keluarga dalam pemberian MPASI dalam setiap kesempatan. 


\section{REFERENSI}

Andarmoyo, S. (2012). Keperawatan Keluarga Konsep Teori, Proses dan Praktik Keperawatan. Yogyakarta: Graha Ilmu.

Anggraenil, I.A., D.S. Nurdiati, \& R. S. P. (2015). Keberhasilan ibu bekerja memberikan asi eksklusif. Jurnal Gizi Dan Dietetik Indonesi, 3(2), 69-76.

Ayuningtiyas. Laksmi W. (2013). Hubungan Pelaksanaan Fungsi Perawatan Kesehatan Keluarga Dengan Pencapaian Tugas Perkembangan Balita Di Bina Keluarga Balita (BKB) Glagahwero Kecamatan Kalisat Jember. Retrieved from https://repository.unej.ac.id/bitstrea m/handle/123456789/3225/Laksmi Wardani Ayuningtiyas 092310101006.pdf?sequence $=1$

Dinas Kesehatan Provinsi Bali. (2017). Profil Kesehatan Provinsi Bali 2017. Retrieved from

https://www.diskes.baliprov.go.id/do wnload/profil-kesehatan-provinsibali-tahun-2017/

Efendy Nasrul. (1998). Dasar-Dasar Keperawatan Kesehatan Masyarakat. Jakarta: EGC.

Friedman. (2010). Buku Ajar Keperawatan keluarga: Riset, Teori, dan Praktek. Jakarta: EGC.

Heryanto. (2017). Asuhan Kebidanan Ibu Nifas Normal. Jurnal Aisy, 2(2), 141$152 . \quad$ Retrieved from https://aisyah.journalpress.id/index.p hp/jika/article/view/EH/pdf

Luluk, L. S. (2005). Resiko Pemberian MP-ASI Dini.

Nadesul, H. (2011). Menyayangi Otak Menjaga Kebugaran, Mencegah Penyakit, Memilih Makanan. Jakarta: Penerbit Buku Kompas.
Notoatmodjo. (2014). Kesehatan Masyarakat Ilmu dan Seni. Rineka Cipta.

nursalam. (2017). metodologi penelitian ilmu keperawatan. JAKARTA: salemba medika.

Pemerintah Republik Indonesia. (2012). Peraturan Pemerintah RI No 33 tentang Pemberian Air Susu Ibu ekslusif. In Republik Indonesia (p. 32). Retrieved from http://hukor.kemkes.go.id/uploads/p roduk_hukum/PP No. 33 ttg Pemberian ASI Eksklusif.pdf

Profil Kesehatan indonesia. (2018). Provil Kesehatan Indonesia 2018 (Vol. 1227). https://doi.org/10.1002/qj

Rahmawati, A., \& Prayogi, B. (2017). Analisis Faktor yang Mempengaruhi Produksi Air Susu Ibu (ASI) pada Ibu Menyusui yang Bekerja. Jurnal Ners Dan Kebidanan (Journal of Ners and Midwifery), 4(2), 134-140. https://doi.org/10.26699/jnk.v4i2.art .p134-140

Ramlah. (2011). Dukungan Keluarga Dengan Pengabaian Lansia Di Wilayah Kerja Puskesmas Kassi-Kassi Ramlah Program Studi Magister Ilmu Keperawatan Lansia Di Wilayah Kerja Puskesmas Kassi-Kassi. Retrieved from http://lontar.ui.ac.id/file?file=digital/ 20281102-T Ramlah.pdf

Roesli Utami. (2004). Bayi sehat berkat ASI Eksklusif, makanan pendamping tepat dan imunisasi lengkap (Agnes M.S, Ed.). Jakarta: Elex Media Komputindo.

Setiadi. (2008). Konsep \& proses keperawatan keluarga. Yogyakarta: Graha Ilmu. 
Suprajitno. (2004). Asuhan Keperawatan Keluarga Aplikasi dalam Praktik. Jakarta: EGC. 